\title{
AERSCIEA: An Efficient and Robust Satellite Color Image Enhancement Approach
}

\author{
Dibya Jyoti Bora \\ Department of Computer \\ Science and Applications, \\ Barkatullah University, Bhopal, India \\ Email: research4dibya@gmail.com
}

\begin{abstract}
Image enhancement is an important preprocessing step in any image analysis process. It helps to catalyze the further image analysis process like Image segmentation. In this paper, an approach for satellite color image enhancement on HSV color space is introduced. Here, local contrast management is given main focus because noises exist on local regions are found over amplified when enhancement is done through global enhancement technique like histogram equalization. The color arrangement and computations are done in HSV color space. The $V$-channel has been extracted for the enhancement process as this is the channel which represents the intensity and thereby represents the luminance of an image. At first, the image is normalized to stabilize the pixel distribution. The normalized image channel is analyzed with Binary Search Based CLAHE (BSB-CLAHE) for local contrast enhancement. The results obtained from the experiments prove the superiority of the proposed approach.
\end{abstract}

Index Terms-Binary Search; CLAHE; Color Image Enhancement; HSV Color Space; Histogram Equalization; Image Normalization; Multispectral Image; MSE; PSNR;RGB Color Space.

\section{INTRODUCTION}

Image enhancement is a major step for any image analysis process. This has to be conducted if the results of the further analysis process are needed to be improved. Most importantly, if it is the case of satellite images, then this becomes a mandatory condition as because most of the satellite images consist of noises. Satellite images use to carry a large amount of information with them, so the presence of noises may hamper the extraction of such huge amount of useful information [1][2][3]. In the case of satellite images, a small block of the whole image concerns a lot, so, local contrast management should be given major priority here. Also, RGB color space is not able to deal with the satellite color image analysis properly [4][5], hence we need a color space which has the ability to arrange the colors in a way so that any change of intensity will not distort the color information of the image. HSV color space has the ability to deal with the color in the same way that human eyes can perceive [6]. It has a separate channel for intensity information (V-channel).
These are the reasons why we have selected HSV color space for the proposed color enhancement approach.

The outline of the paper is as follows: Section II presents a review of the previous work done in the field; Section III discusses the different steps involved in the proposed approach. From section IV to section VI, the topics involved in the proposed approach are explained with proper examples. Section VII is the experiment and results discussion section. The conclusion is given in the section VIII and finally, we have the reference section

\section{Literature Review}

In [7], an underwater image enhancement technique has been proposed which is a novel extension of histogram equalization (histogram specification) to overcome BPHEME (Brightness Preserving Histogram Equalization with Maximum Entropy), a drawback of Histogram Equalization. The experimental results claim that BPHEME enhances the image effectively and also preserve the original brightness quite well.

In [8], a new contrast enhancement technique for satellite images based on clipping or plateau histogram equalization is proposed. Here, a Bi-Histogram Equalization with Plateau Limit (BHEPL) is adopted for image decomposition and Self-Adaptive Plateau Histogram Equalization (SAPHE) for threshold calculation. The proposed enhancement technique performs comparatively better than the other available histogram equalization technique.

In [9], a genetic algorithm (GA) based histogram equalization technique is proposed. Here, images are enhanced with histogram equalization by reconfiguring their pixel spacing using optimization through GA. The results obtained are more optimized than the same done by other available techniques

In [10], here the value channel of the HSV converted the image of the input RGB color image is enhanced in two steps: (1) It is divided into smaller blocks and in each block dynamic range compression is carried out using nonlinear transfer function, and (2)In each block, every pixel is further 
enhanced depending upon the centre pixel and its neighborhood so that the contrast of the image has been adjusted. Then it is converted back to RGB. The experiments results show the better performance of the proposed approach.

In [11], the authors propose a new underwater image enhancement technique known as mixture CLAHE color models. The proposed method operates CLAHE on RGB and HSV color models. Results obtained from both are combined together using Euclidean norm. This approach significantly improves the visual quality of underwater images by enhancing contrast, as well as reducing noise and artifacts.

\section{THE STEPS INVOLVED IN THE PROPOSED APPROACH}

Step1. The input RGB color image is undergone conversion to HSV color space.

Step2. The Value channel (V Channel) has been extracted from the HSV converted the image. The V channel has been chosen as this represents the luminance of the image. Another important fact is that $\mathrm{H}$ (Hue) channel should not be affected during the enhancement process as otherwise color information may be misjudged.

Step3. The extracted V channel has been normalized between $o$ and 1 to bring stability to the pixel distribution.

Step4. The normalized V Channel has been undergone local contrast management by BSB-CLAHE (Binary Search Based-CLAHE).

Step5. The old V-channel has been replaced by the enhanced V channel to obtain the enhanced HSV image.

Step6. The Enhanced HSV image is converted back to RGB color space to obtain the final enhanced image of the original input color image.

\section{HSV COLOR SPACE:}

Color space can be defined as a mathematical model used to describe the organization of different colors of an image. It represents different color attributes with respect to three or more components that help to learn accurately how each color spectrum looks like [4][12]. HSV is one of such frequently adopted color space because of its efficiency in organizing any color image in the same way that our human eyes can perceive. In this color space, there are three channels: Hue $(\mathrm{H})$, Saturation $(\mathrm{S})$ and Value $(\mathrm{V})$. The first one represents an angle in the range $[0,2 \pi]$ and is directly related to color. Different hue angles represent different colors. The second one, i.e., $\mathrm{S}$ channel shows how pure the hue is with respect to a white reference. This can be thought of as a radial distance from the central axis whose value is 0 at the center to 1 at the outer surface. Finally, the value represents a percentage value goes from 0 to 100 . This percentage value exactly shows the amount of light illuminated with respect a particular color. This means Vchannel is the luminance channel in HSV color space. So, with the ' $\mathrm{V}$ ' channel of HSV color space, it is possible to measure and extract the luminance level of a color image, which makes it perfect color space for color image enhancement and also for color image segmentation [4]. A pseudo code to convert an RGB image into HSV color space can be found in [13].

The coordinate system showing the relationship between the three channels of HSV color space is shown in the following figure:

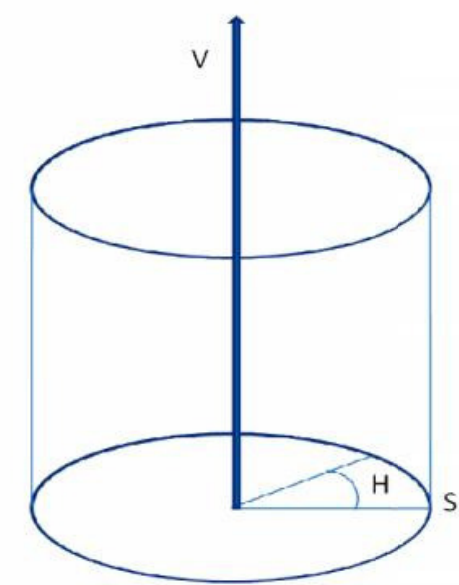

Fig. 1: HSV Color Space Showing the Relation between H, S, and V

The distribution of different colors with respect to Hue values (ranges 0 to $2 \pi$ ) can be shown in the following color wheel diagram. The color first started with red, as the Hue value changes, then it changes in the following pattern:

red $\rightarrow$ yellow $\rightarrow$ green $\rightarrow$ cyan $\rightarrow$ blue $\rightarrow$ magenta $\rightarrow$ red.

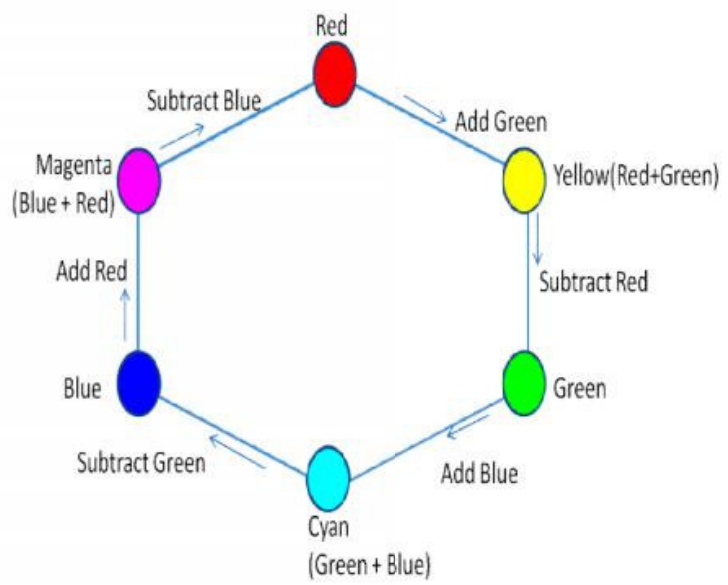

Fig. 2: Color Wheel Showing Distribution of Different Colors in HSV Color Space With Respect to Different Values of V 


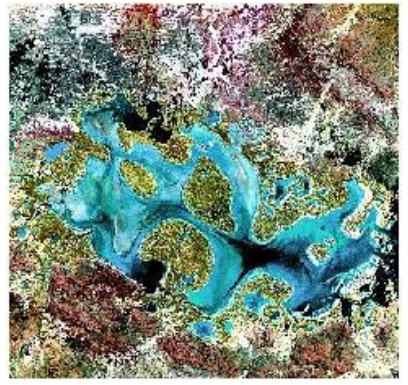

(a)

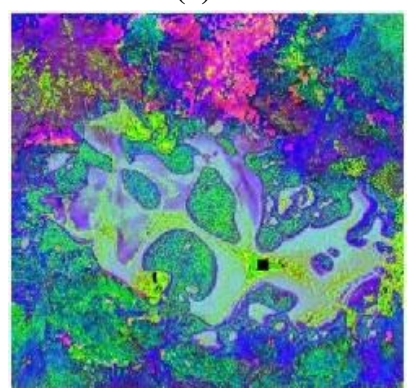

(b)

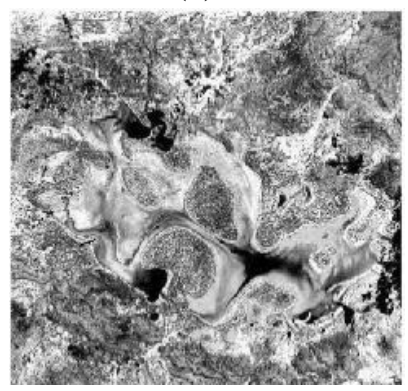

(c)

Fig. 3: (a)Original Satellite Image in RGB; (b) HSV Converted image of (a); and (c) The V-Channel of HSV Converted Image of (b).

\section{IMAGE NORMALIZATION}

In general 'normalization' can be considered as a preprocessing stage to find out a new stable range from an existing one[14]. While when the concerned area is image processing, then 'image normalization' can be defined as a technique for changing the ranges of pixel intensity values and thereby bringing stability to it [15]. Normalization of the image is required in order to shape the pixels of the image into a range that is more proverbial to the dealt application. Image variations may occur during image acquisition process. These variations may take different forms like illumination, noise or occlusion which are no way relevant to object identity. So, we need a process to eliminate such unwanted variations to retain a standard image containing no artifacts. Image normalization is such a process to make the image artifact free and thereby get it ready for the further image analysis process [15][16]. This way the accuracy of the image enhancement can be increased to a satisfiable extent. In our proposed approach, the V channel of the HSV converted image has been normalized and bring its range to fall within 0 and 1 . Following equation performs this task: Say, V1 is the current V-value and V2 is the normalized one. $\mathrm{V} 2=\{\mathrm{V} 1-$ minimum $(\mathrm{V} 1)\} /\{$ maximum $(\mathrm{V} 1)$-minimum $(\mathrm{V} 1)\}$;

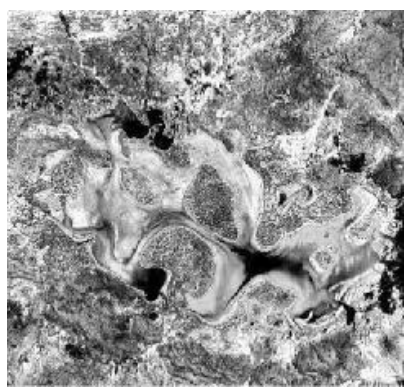

(a)

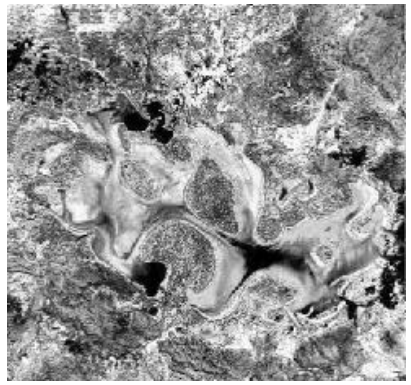

(b)

Fig. 4: (a)V Channel; (b) Normalized V Channel.

In figure 5,( b) is the normalized version of (a) obtained through the application of the above equation.

\section{BINARY SEARCH BASED CLAHE (BSB-CLAHE)}

Contrast management is one of the most needed steps involved in an image enhancement process. With this, the contrast of an image can be modified to a satisfactory level such that the result of the whole image analysis process becomes more efficient. Contrast management is of two types: (1) Global contrast management and, (2) local contrast management. Histogram Equalization (HE) is an example of global contrast management and Adaptive Histogram Equalization (AHE)[17] is an example of local contrast management. Histogram equalization is a frequently adopted image enhancement technique which enhances the contrast of an image by spreading the intensities values over the entire available dynamic range [1][4].But, it has a drawback that it tends to over enhance the image contrast if there are high peaks in the histogram [18]. AHE works on the basis of computing several histograms and using them to redistribute the lightness values of the image [19][20]. But, its main drawback is that it over amplify the noises in homogenous 
regions. For this reason, we have gone for the other option that is CLAHE. CLAHE means we need to put a limit on the contrast enhancement. For some intensity levels, the slope of the CDF (Cumulative Distributive Function) at the intensity level is directly proportional to the contrast enhancement of those intensity levels [4][20]. Again, at a bin location, the slope of the CDF can be determined by the height of the histogram for that concerned bin. This implies that by limiting or clipping the height of the histogram to a certain level, we can limit the slope of the CDF function and thereby the contrast enhancement can be limited [4]. So, the only thing we need a mechanism for clipping the histogram before evaluating its $\mathrm{CDF}$ for putting a limit on the contrast enhancement done by AHE. For this, we have introduced Binary Search Based CLAHE. Here, we have adopted a Binary Search Method [4][17][21] for determining the points at which the clipping should be done. The algorithm is discussed below:

\begin{tabular}{|l|}
\hline Step1. Say Tis the top and B is the bottomof the concemed CipLevel. \\
Step2 Repeat until $\mathrm{T}-\mathrm{B}<\epsilon$, were $\ominus 0$ is negligibly small \\
{$[a]$ Find $M$ where Mis the middle between T and B } \\
{$[b]$ Find $S$ where Sis the sum of excess above M in each bin of the histogram } \\
{$[c]$ if $S+M>$ CipLevel } \\
then assign $T=M$ \\
{$[d]$ if $S+M<$ CipLevel } \\
then assign $B=M$ \\
{$[e]$ if $S+M=$ CipLevel } \\
then Mis the required value at which clipping should be done. So, break binary searchloop. \\
Step3. Cip the histogramat Mand redistribute the excess into each bin equally.
\end{tabular}

\section{EXPERIMENTS AND RESULTS}

Matlab is chosen for implementation of our proposed approach. The system used for conducting the experiments has an i5 processor with 64 bit Windows 10 operating system. The satellite image data are collected from Earth Science World Image Bank [22] and The USC-SIPI Image Database [23].

To measure the quality of the enhancement results, we have selected the MSE (Mean Squared Error) and PSNR (Peak Signal to Noise Ratio) metric. The cumulative squared error between the compressed and the original image will be given by the first one, whereas the second one will give the peak error [24][25]. Following equation [2] is used calculate $M S E$

$M S E=\sum_{y=1}^{M} \sum_{x=1}^{N}\left[I(x, y)-I^{\prime}(x, y)\right]^{2}$

where, $I(x, y)$ is the original input color image, $I^{\prime}(x, y)$ is the output enhanced image. $\mathrm{M}, \mathrm{N}$ stands for the dimensions of the images.

The formula for PSNR[25] is:

$\mathrm{PSNR}=10 \log _{10}\left(M A X i^{2} / M S E\right)$
Where $M A X_{i}$ contains the maximum possible pixel value of the image. For a better enhancement of the image, the MSE value should be as low as possible and PSNR values should be as higher as possible.

The following is the series of images illustrating the results obtained at every stage of the proposed approach. The image is the aerial image of San Francisco (Golden Gate) consisting of $512 \times 512$ pixels with size $768 \mathrm{~kb}$.

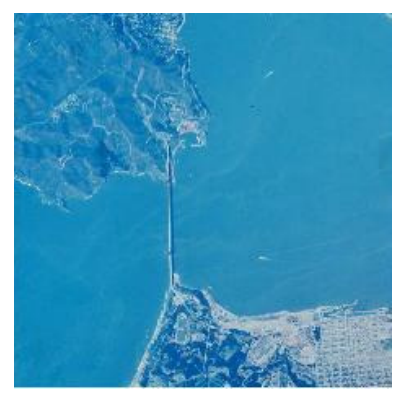

(a)

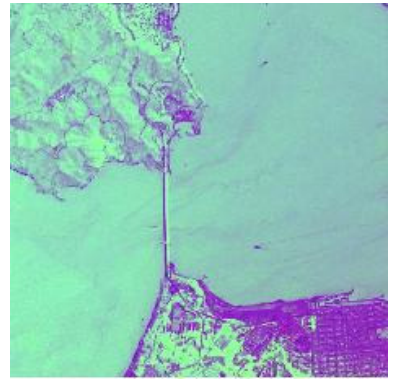

(b)

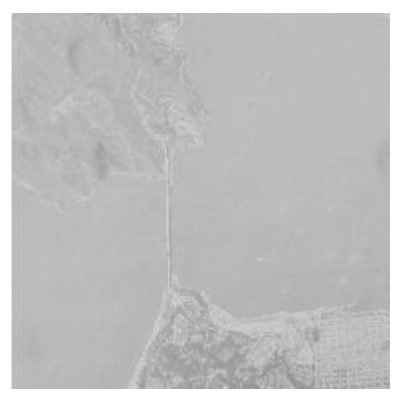

(c)

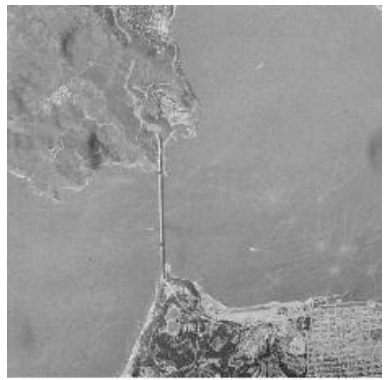

(d) 


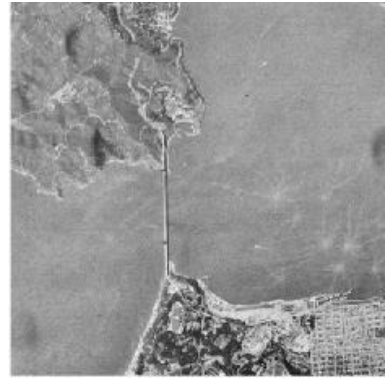

(e)

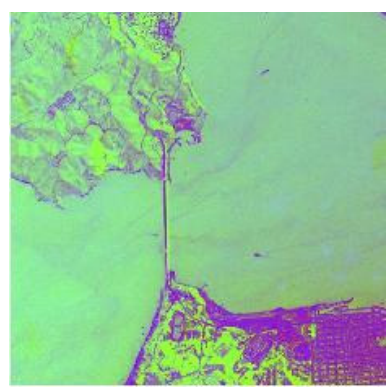

(f)

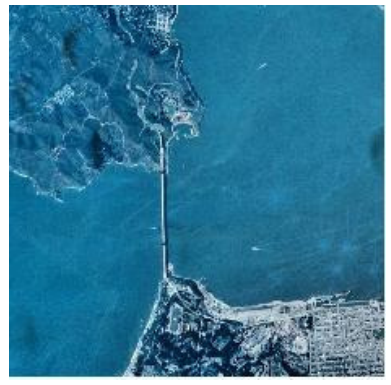

(g)

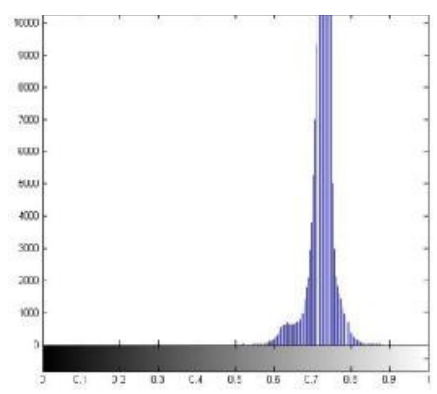

(h)

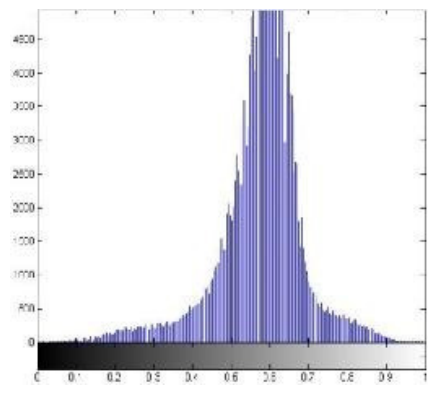

(i)

Fig. 5: (a) Original Image; (b) HSV Converted Image; (c) V-Channel; (d)Normalized V-Channel; (e) BSB-CLAHE Enhanced V-Channel; (f)Enhanced Image in HSV Color space; (g) Final Enhanced Color Image; (h) Histogram of the Original V-Channel; and (i) Histogram of the enhanced V-Channel by Our Proposed Approach.

The proposed approach has been applied to around 30 different satellite images. To compare the results with existent state of the art algorithms, we have selected D.Ghimire'sMethod $[10]$ as the recent one in the area. Also, as Histogram Equalization is the most popular and frequently adopted method for image enhancement, so this is selected for comparing the same. The results for 4 images are shown below:

Image 1: This is the image of Woodland Hills, Ca.[23] consisting of $512 \times 512$ pixels with size $768 \mathrm{~kb}$.

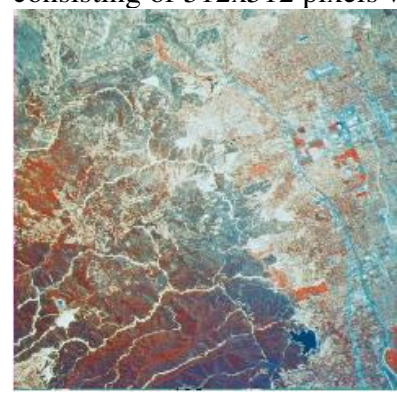

(a)

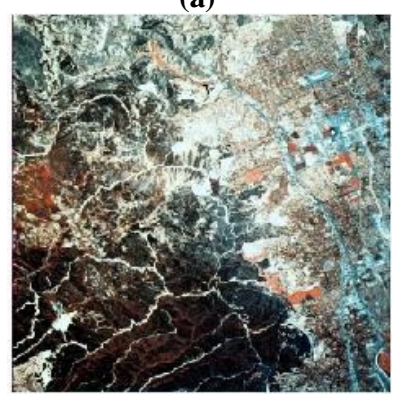

(b) 


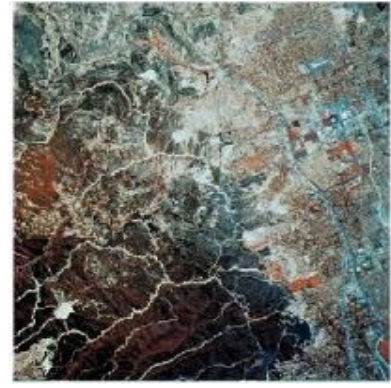

(c)

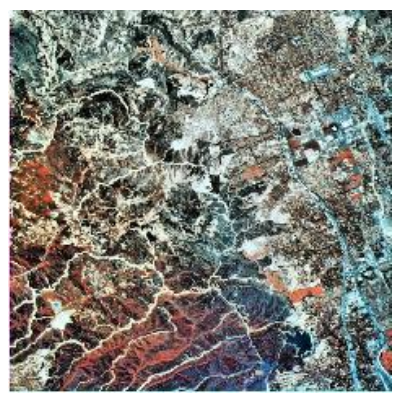

(d)

Fig. 6: (a) Original Image; (b) Enhanced Image by Histogram Equalization; (c) Enhanced Image By D. Ghimire's Method; (d) Enhanced Image by the Proposed Approach.

Table 1: MSE Values

\begin{tabular}{|l|l|l|l|}
\hline MSE & $\begin{array}{l}\text { Proposed } \\
\text { Approach }\end{array}$ & $\begin{array}{l}\text { Histogram } \\
\text { Equalization }\end{array}$ & $\begin{array}{l}\text { D. Ghimire's } \\
\text { Method }\end{array}$ \\
\hline MSE(:,:,1) & 548.9040 & 568.7403 & 550.1531 \\
\hline MSE(:::,2) & 485.4190 & 486.4923 & 485.9121 \\
\hline MSE(:::,3) & 489.5610 & 499.0934 & 491.8147 \\
\hline
\end{tabular}

\begin{tabular}{|l|l|l|l|}
\hline PSNR & $\begin{array}{l}\text { Proposed } \\
\text { Approach }\end{array}$ & $\begin{array}{l}\text { Histogram } \\
\text { Equalization }\end{array}$ & $\begin{array}{l}\text { D. } \\
\text { Ghimire's } \\
\text { Method }\end{array}$ \\
\hline PSNR(::,:1) & 20.7358 & 20.5817 & 20.7260 \\
\hline PSNR(::,:2) & 21.2696 & 21.2600 & 21.2652 \\
\hline PSNR(::,:3) & 21.2327 & 21.1490 & 21.2128 \\
\hline
\end{tabular}

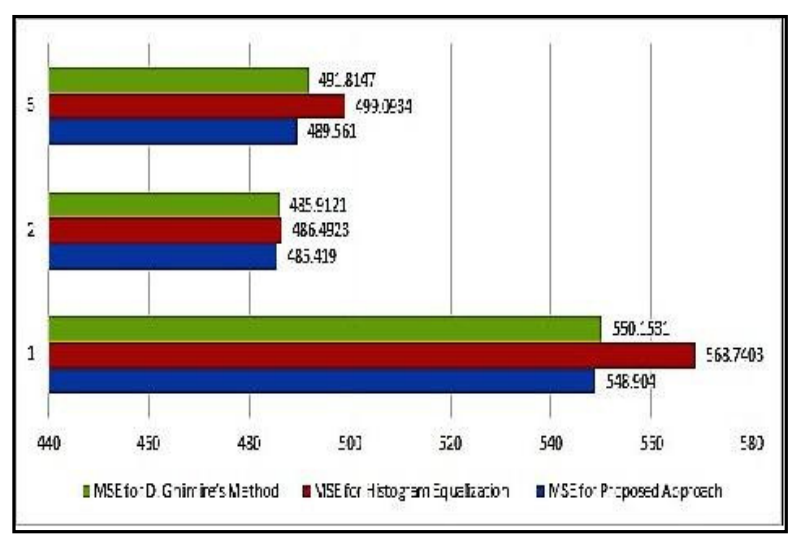

(a)

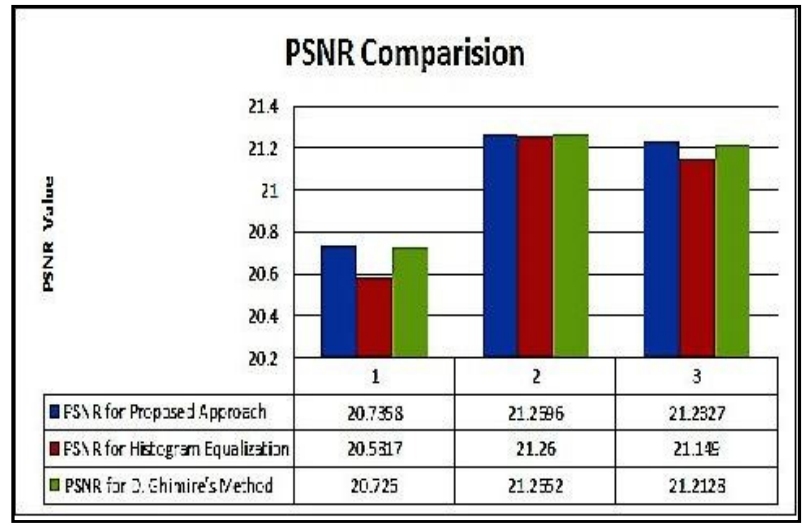

(b)

Chart 1: (a) MSE Values Comparison; and (b) PSNR Values Comparison.

Image 2: This is the image of Stockton [23] consisting of $1024 \times 1024$ pixels and of size $3072 \mathrm{~kb}$.

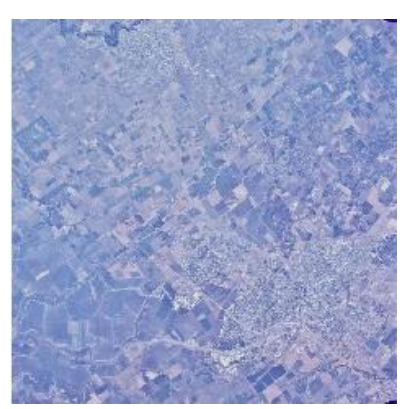

(a) 


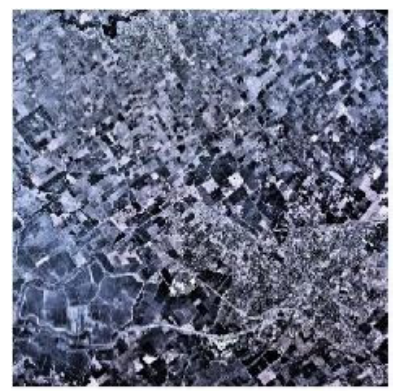

(b)

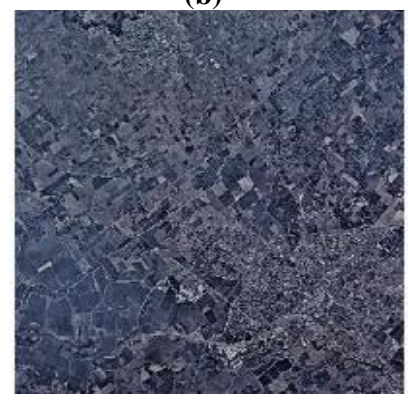

(c)

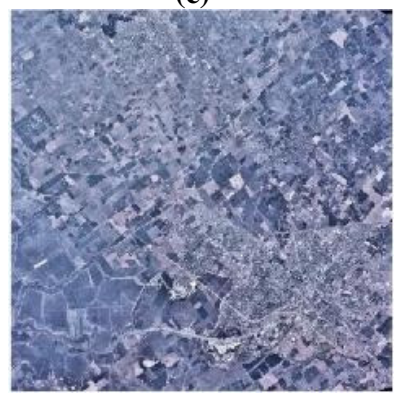

(d)

Fig. 7: (a) Original Image; (b) Enhanced Image by Histogram Equalization; (c) Enhanced Image By D. Ghimire's Method; (d) Enhanced Image by the Proposed Approach.

Table 3: MSE Values

\begin{tabular}{|l|c|c|l|}
\hline MSE & $\begin{array}{l}\text { Proposed } \\
\text { Approach }\end{array}$ & $\begin{array}{l}\text { Histogram } \\
\text { Equalization }\end{array}$ & $\begin{array}{l}\text { D.Ghimire's } \\
\text { Method }\end{array}$ \\
\hline MSE(:,:,1) & 213.9250 & 990.0254 & 230.1491 \\
\hline MSE(::,:2) & 245.8646 & $1.1458 \mathrm{e}+03$ & 251.7132 \\
\hline MSE(::,:3) & 402.3137 & $1.8729 \mathrm{e}+03$ & 412.9015 \\
\hline
\end{tabular}

Table 4: PSNR Values

\begin{tabular}{|l|l|l|l|}
\hline PSNR & $\begin{array}{l}\text { Proposed } \\
\text { Approach }\end{array}$ & $\begin{array}{l}\text { Histogram } \\
\text { Equalization }\end{array}$ & $\begin{array}{l}\text { D. } \\
\text { Ghimire's } \\
\text { Method }\end{array}$ \\
\hline PSNR(:,:,1) & 24.8282 & 18.1743 & 24.5107 \\
\hline PSNR(:,:,2) & 24.2238 & 17.5396 & 24.1217 \\
\hline PSNR(:,:,3) & 22.0852 & 15.4056 & 21.9723 \\
\hline
\end{tabular}

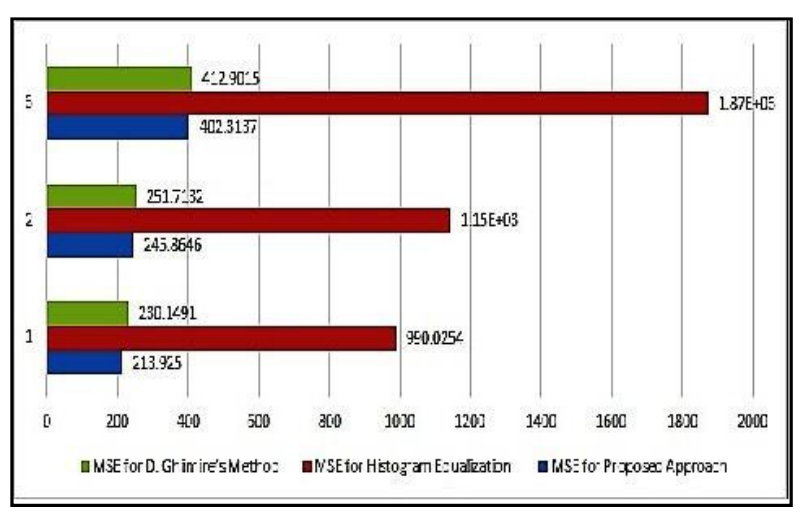

(a)

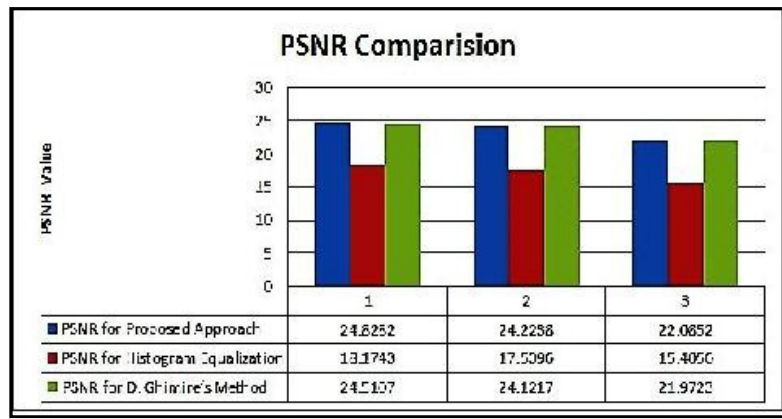

(b)

Chart 2: (a) MSE Values Comparison; and (b) PSNR Values Comparison.

Image 3: This is the image of The Bruneau River[22]. The image is consisting of 512 x 512 pixels and of size $30.7 \mathrm{~kb}$.

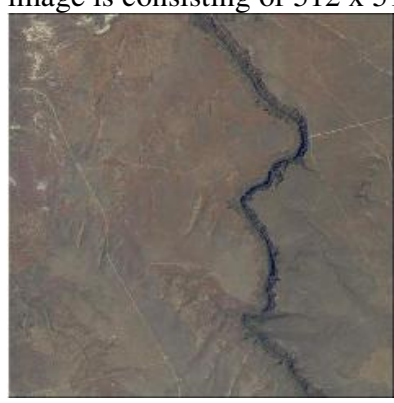

(a)

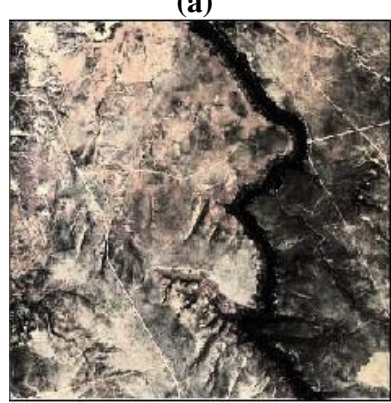

(b) 


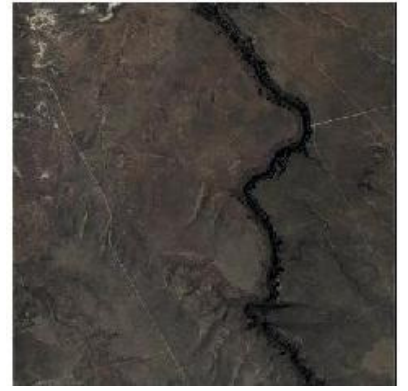

(c)

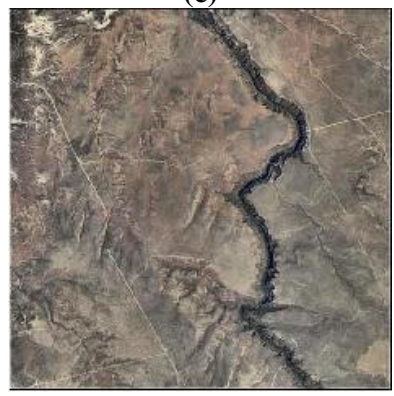

(d)

Fig 8: (a) Original Image; (b) Enhanced Image by Histogram Equalization; (c) Enhanced Image By D. Ghimire's Method; (d) Enhanced Image by the Proposed Approach.

Table 5: MSE Values

\begin{tabular}{||l|l|l|l|}
\hline MSE & $\begin{array}{l}\text { Histogram } \\
\text { Equalization }\end{array}$ & $\begin{array}{l}\text { D. Ghimire's } \\
\text { Method }\end{array}$ & $\begin{array}{l}\text { Proposed } \\
\text { Approach }\end{array}$ \\
\hline MSE(:::,1) & 860.3721 & 614.7396 & 126.0805 \\
\hline MSE(:::,2) & 762.1873 & 520.3671 & 111.9851 \\
\hline MSE(:::,3) & 673.6254 & 434.4569 & 98.3249 \\
\hline
\end{tabular}

Table 6: PSNR Values

\begin{tabular}{|l|l|l|l|}
\hline PSNR & $\begin{array}{l}\text { Histogram } \\
\text { Equalization }\end{array}$ & $\begin{array}{l}\text { D. } \\
\text { Ghimire's } \\
\text { Method }\end{array}$ & $\begin{array}{l}\text { Proposed } \\
\text { Approach }\end{array}$ \\
\hline PSNR(:::,1) & 18.7839 & 20.2439 & 27.1243 \\
\hline PSNR(:::,2) & 19.3102 & 20.9677 & 27.6392 \\
\hline PSNR(:::,3) & 19.8466 & 21.7513 & 28.2042 \\
\hline
\end{tabular}

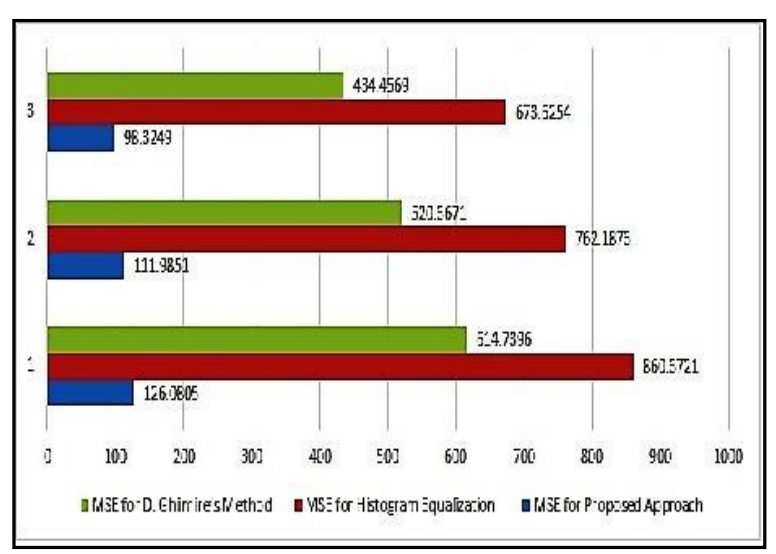

(a)

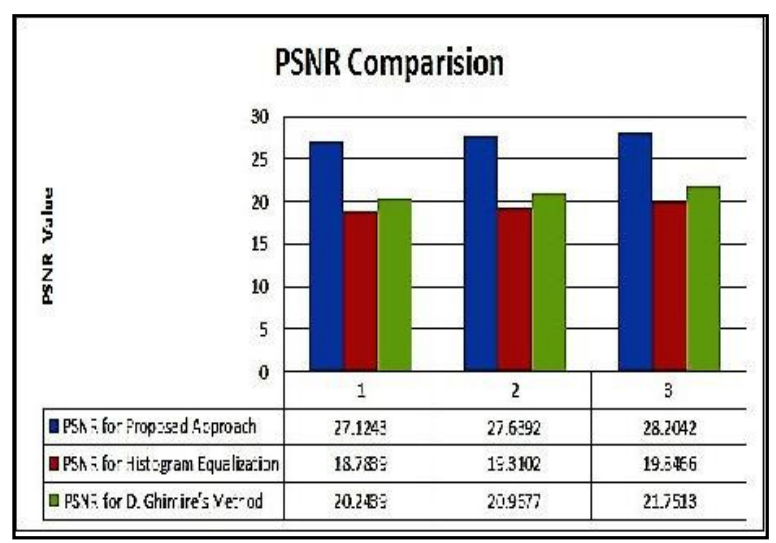

(b)

Chart 3: (a) MSE Values Comparison; and (b) PSNR Values Comparison.

Image 4: This image of South Atlantic Ocean east of the Falkland Islands [22] showing numerous eddies highlighted by phytoplankton. The image is consisting of $464 \times 512$ pixels and of size $38.8 \mathrm{~kb}$. Salt and pepper noise of density 0.04 is added to this image and then performed the enhancement by the proposed approach, D. Ghimire's Method, and histogram equalization. Results are shown below:

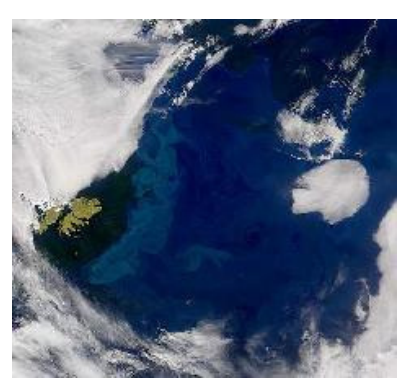

(a) 


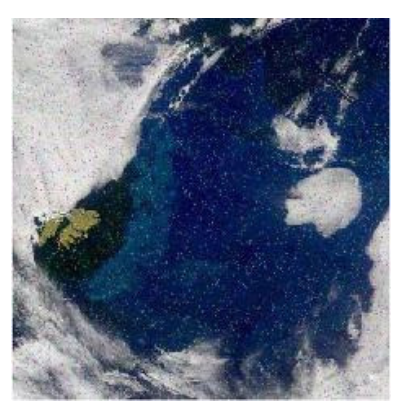

(b)

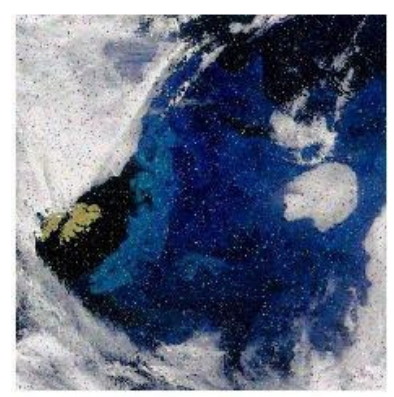

(c)

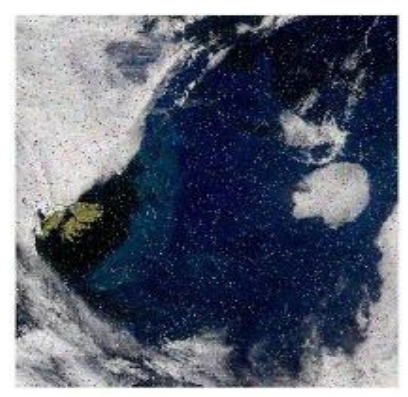

(d)

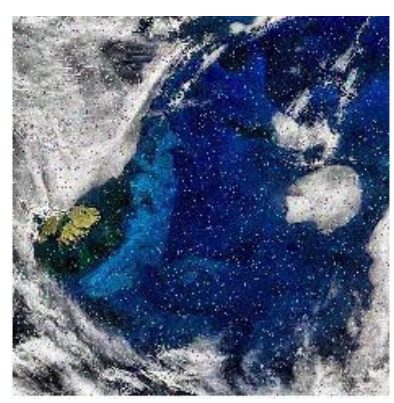

(e)

Fig. 9: (a) Original Image; (b) Noisy Image; (c) Enhanced Image By Histogram Equalization, (d) Enhanced Image By D. Ghimire's Method; and (e) Enhanced Image By the Proposed Approach
Table 7: MSE Values

\begin{tabular}{|l|l|l|l|}
\hline MSE & $\begin{array}{l}\text { Proposed } \\
\text { Approach }\end{array}$ & $\begin{array}{l}\text { Histogram } \\
\text { Equalization }\end{array}$ & $\begin{array}{l}\text { D.Ghimire's } \\
\text { Method }\end{array}$ \\
\hline MSE(:,:,1) & 120.5921 & 128.1954 & 122.5612 \\
\hline $\operatorname{MSE}(:,:, 2)$ & 130.7515 & 141.0957 & 130.7821 \\
\hline $\operatorname{MSE}(:,:, 3)$ & 177.5191 & 178.9520 & 179.1521 \\
\hline
\end{tabular}

Table 8: PSNR Values

\begin{tabular}{|l|l|l|l|}
\hline PSNR & $\begin{array}{l}\text { Proposed } \\
\text { Approach }\end{array}$ & $\begin{array}{l}\text { Histogram } \\
\text { Equalization }\end{array}$ & $\begin{array}{l}\text { D.Ghimire's } \\
\text { Method }\end{array}$ \\
\hline PSNR(:,:,1) & 27.3176 & 27.0521 & 27.2473 \\
\hline PSNR(::,:2) & 26.9663 & 26.6357 & 26.9653 \\
\hline PSNR(::,:3) & 25.6384 & 25.6034 & 25.5986 \\
\hline
\end{tabular}

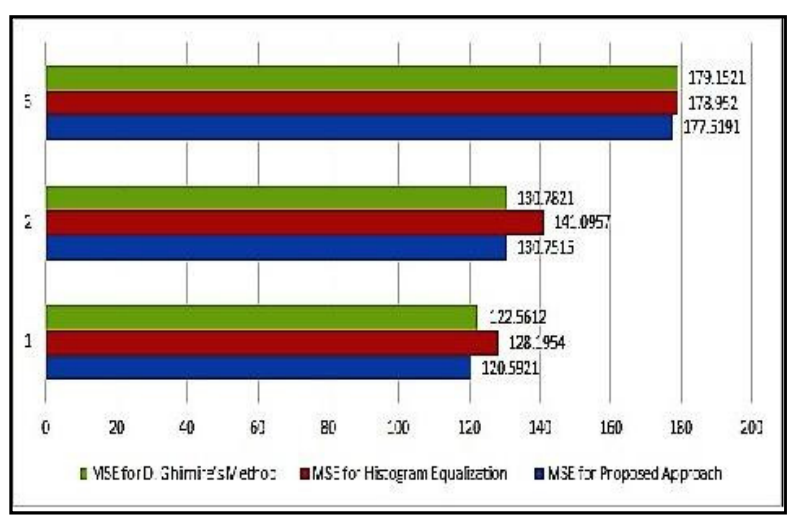

(a)

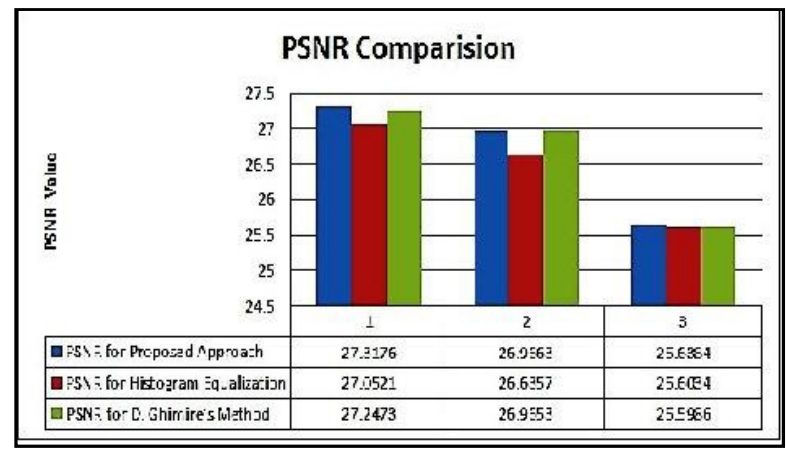

(b)

Chart 4: (a) MSE Values Comparison; and (b) PSNR Values Comparison.

So, from the experimental results, it is observed that the enhancement done by our proposed approach is noise free, and every little region is enhanced equally with clear identification of the present objects. While the results 
obtained by the histogram equalization are somewhat noise over amplified and thereby appearance of high darkness shades are found in the resultant image. D.Ghimire's Method succeeds to produce good enhancement. But, visually the enhancement results of our proposed approach are better than both the Histogram Equalization and D.Ghimire's Method. The MSE values for all the images are found low for the proposed approach in comparison to histogram equalization and D.Ghimire's Method, while the respective PSNR values for the proposed approach are higher than the same of histogram equalization and. Also, in the case of image 4, we have seen the proposed approach is producing a better result even in the situation when salt and pepper noises are added to the input color image. This implies that the proposed approach succeeds to produce better enhancement of satellite color image than histogram equalization and D. Ghimire's Method.

\section{Multispectral Image:}

A multispectral image is an image that captures image data at specific frequencies across the electromagnetic spectrum[26]. The spectrum is generally divided into many bands. Each band is a monochrome image of the scene taken with a different sensor. As for example, Landsat 5 consists of 7 band images with the wavelength of the bands being between 450 and $1250 \mathrm{~nm}$. Multispectral images mostly used in remote sensing applications [27]. It is found that there has always been a need of enhancing multispectral radiance data to produce an image that will be more suitable for visual interpretation. To analyze the efficiency of our proposed approach in enhancing the multispectral image, we have collected a LAN file, paris.lan, containing a 7-band 512-by512 Landsat image which covers a part of Paris, France. [28]. The bands 3, 2, and 1 from this LAN file are read and mapped to the red, green, and blue planes, respectively, of an RGB image, the result is a standard truecolor composite. The image has been undergone enhancement with three different techniques: Histogram Equalization, D.Ghimire'sMethod and our proposed approach. The results are shown below:

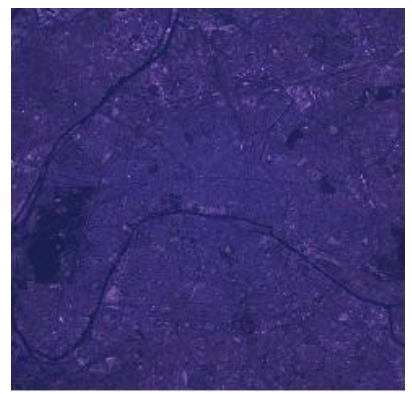

(a)

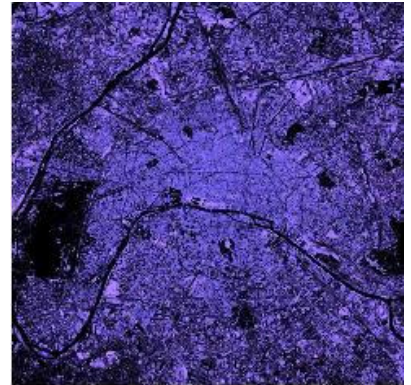

(b)

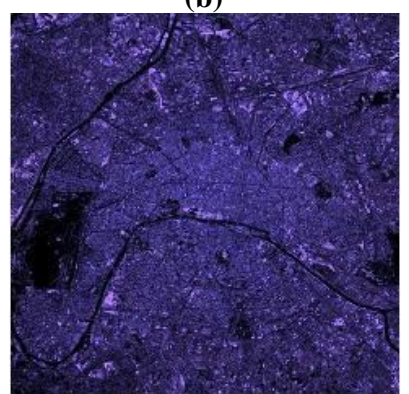

(c)

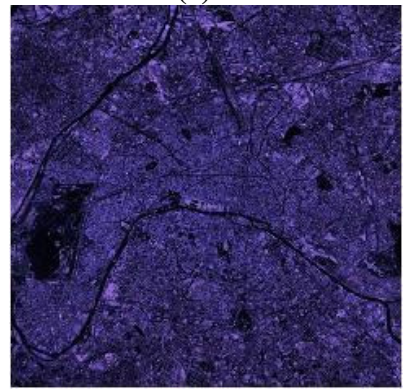

(d)

Fig. 10: (a) Original Image; (b) Enhanced Image by Histogram Equalization; (c) Enhanced Image By D. Ghimire's Method; (d) Enhanced Image by the Proposed Approach.

From the results, it is clearly visible that histogram equalization is producing over enhancement of the contrast of the original multispectral image. In this case, both the techniques: D. Ghimire's Method and our proposed method succeeds to deal with the over enhancement problem. But, the proposed approach is producing better enhancement of the image because of the fact that the normalized distribution of the concerned V-channel makes it easier to enhance the local contrast more efficiently and thereby resulting in a smooth global contrast enhancement of the image.

\section{Conclusion:}

In any image analysis process, image enhancement is always considered as an important preprocessing step. Through image enhancement, the noises or irrelevant information is tried to remove to the maximum possible extent. Contrast management is one of the important tasks during enhancement process. It is of two types: global and local. Global contrast management although possessing low 
computational complexity, but fails to produce better enhancement results and maximum times enhanced images are found suffering from noises. So, local contrast management is needed for better enhancement. In this paper, a BSB-CLAHE based enhancement technique for satellite color images is introduced where local contrast management is given main focus. The enhancement process is done on HSV color space because of its capability to deal with satellite image in a far better way than RGB color space does. Normalization procedure is adopted here to bring stability in the range of pixels distribution of the input color image. The results of the proposed approach are found quite satisfactory and hence establish a good framework for satellite color image enhancement. In future, the application of the proposed approach will be extended to different emerging areas like medical color image enhancement, underwater color image enhancement etc.

\section{REFERENCES}

[1] R. C. Gonzalez and R. E.Woods, "Digital Image Processing", Third Edition, 2008.

[2] B. Sreenivas, B. N. Chary, "Processing Of Satellite Image Using Digital Image Processing", A world forum on Geospatial, January - 2011

[3] D. J. Bora, A. K. Gupta, "A New Efficient Color Image Segmentation Approach Based onCombination of Histogram Equalization with Watershed Algorithm", International Journal of Computer Sciences and Engineering Vol.-4(6), Jun 2016, EISSN: 2347-2693,pp. 156-167.

[4] D. J. Bora, A. K. Gupta, "AERASCIS: An Efficient and Robust Approach for Satellite Color Image Segmentation", IEEE International Conference on Electrical Power and Energy Systems (ICEPES), Maulana Azad National Institute of Technology, Bhopal, India. Dec 14-16, 2016.

[5] A. K. Gupta, D. J. Bora, "A Novel Color Image Segmentation Approach Based On K-Means Clustering with Proper Determination of the Number of Clusters and Suitable Distance Metric", International Journal of Computer Science \& Engineering Technology (IJCSET), Vol. 7 No. 09 Sep 2016, pp. 395-409.

[6] D. J. Bora, A. K. Gupta, "A New Approach towards Clustering based Color Image Segmentation", International Journal of Computer Applications $(0975$ - 8887), Volume 107 - No 12, December 2014, pp. 23-30.

[7] J. Singh ,P.Rawat, "Image enhancement method for underwater, ground and satellite images using brightness preserving histogram equalization with maximum entropy", International Conference on Computational Intelligence and Multimedia Applications (ICCIMA 2007), Sivakasi, Tamil Nadu, 2007, pp. 507-512.

[8] R. Aedla, G. S. Dwarakish,D. V. Reddy, "Satellite image contrast enhancement algorithm based on plateau histogram equalization", 2014 IEEE REGION 10 SYMPOSIUM, Kuala Lumpur, 2014, pp. 213-218.

[9] Chahat, M. K. Patil, "Image Enhancement Using Histogram Equalization Based On Genetic Algorithm", International Journal of Engineering Research and Development e-ISSN:
2278-067X, p-ISSN: 2278-800X, www.ijerd.com, Volume 7, Issue 8 (June 2013), pp. 12-17.

[10] D. Ghimire , J. Lee, "Color Image Enhancement in HSV Space Using Nonlinear Transfer Function and Neighborhood Dependent Approach with Preserving Details", 2010 Fourth Pacific-Rim Symposium on Image and Video Technology, Singapore, 2010, pp. 422-426.

[11] M. S. Hitam, E. A. Awalludin, W. N. JawahirHj Wan Yussof, Z. Bachok, "Mixture contrast limited adaptive histogram equalization for underwater image enhancement", 2013 International Conference on Computer Applications Technology (ICCAT), Sousse, 2013, pp. 1-5.

[12] Stephen Johnson, "Stephen Johnson on Digital Photography". O'Reilly, 2006, ISBN 0-596-52370-X.

[13] A.. Koschan, M. Abidi, "Digital Color Image Processing", Wiley-Interscience New York, NY, USA (02008, ISBN:04701470839780470147085.

[14] L.A.Shalabi, Z. Shaaban, B. Kasasbeh, " Data Mining: A Preprocessing Engine", J. Comput. Sci., 2:2006, pp. 735-739.

[15] Normalization (image processing), WebLink: https://en.wikipedia.org/wiki/Normalization_(image_processing)

[16] E. Bart, S. Ullman, “ Image normalization by mutual information", in Proc. BMVC, 2004, pp. 327-336.

[17] S. M. Pizer, E. P Amburn, J. D. Austin, R. Cromartie, A. Geselowitz, T. Greer, B. T. H. Romeny, J. B Zimmerman, K. Zuiderveld, "Adaptive histogram equalization and its variations", Computer Vision, Graphics, and Image Processing 39, 3 (Sept.), 1987, pp. 355-368.

[18] P. Ganesan, V. Rajini, "Value based semi automatic segmentation of satellite images using HSV color space, histogram equalization and modified FCM clustering algorithm," Green Computing, Communication and Conservation of Energy (ICGCE), 2013 International Conference on, Chennai, 2013, pp. 77-82.

[19] D. J. Ketcham, R. W. Lowe, J. W. Weber, "Image enhancement techniques for cockpit displays", Tech. rep., Hughes Aircraft, 1974.

[20] B.S. Min , D. K. Lim , S. J. Kim, J. H. Lee, "A Novel Method of Determining Parameters of CLAHE Based on Image Entropy", International Journal of Software Engineering and Its Applications, Vol.7, No.5 (2013), pp.113-120.

[21] S.Philip, "Contrast Limited Adaptive Histogram Equalization", Web link:http://www.cs.utah.edu/ sujin/courses/reports/cs6640/projec t2/clahe.html.

[22] Earth Science World Image Bank, Web Link: http://www.earthscienceworld.org/images/.

[23] The USC-SIPI Image Database, Web Link: http://sipi.usc.edu/database/.

[24] Q. Huynh-Thu, M. Ghanbari, "Scope of validity of PSNR in image/video quality assessment," Electronics Letters, vol. 44, no. 13 ,June 2008 , pp. $800-801$.

[25] T. Veldhuizen. "Measures of image quality," 2010,Web Link: http://homepages.inf.ed.ac.uk/rbf/CVonline/LOCAL_COPIES/V ELDHUIZEN/node18.html.

[26] Multispectral Image,Web Link: https://en.wikipedia.org/wiki/Multispectral image.

[27] R.A. Schowengerdt, "Remote sensing: Models and methods for image processing", Academic Press, 3rd ed., 2007.

[28] Image Processing Toolbox,Web Link: https://in.mathworks.com/help/images/. R. W. Lucky, "Automatic equalization for digital communication," Bell Syst. Tech. J., vol. 44, no. 4, pp. 547-588, Apr. 1965. 